\title{
PRÁTICA MÉDICA E DIRETIVAS ANTECIPADAS DE VONTADE: UMA ANÁLISE ÉTICO-JURÍDICA DA CONFORMAÇÃO HARMÔNICA ENTRE OS PRESSUPOSTOS AUTONOMIA E ALTERIDADE
}

Ana Thereza Meireles Araújo*

Mônica Neves Aguiar da Silva**

SUMÁRIO: Introdução; 2 A complexa situação da finitude da vida bumana; 3 As Diretivas Antecipadas de Vontade no direito brasileiro; 3.1 Noções elementares sobre autonomia; 3.20 pressuposto da ortotanásia; 4 A atuação médica em face dos modelos de autonomia; $4.1 \mathrm{~A}$ incidência dos modelos; $4.2 \mathrm{~A}$ adequação do exercício do modelo dos melhores interesses e o pressuposto da alteridade; 5 Considerações finais; Referências.

RESUMO: Artigo destinado à avaliação da adequada conformação prática da atuação médica considerando os modelos de autonomia pertinentes ao procedimento das Diretivas Antecipadas de Vontade, conhecidas também como Testamento Vital, e o pressuposto da alteridade. A autonomia dos melhores interesses, reconhecida pela proposta da bioética principialista, pode ser consubstanciada pelo exercício da capacidade decisória do médico, que pode ir de encontro à perspectiva decisória almejada pelo paciente, mas deve ser calcada no horizonte proposto pelo sentido de alteridade. Tem-se como objetivo o delineamento claro da medida de atuação da decisão médica em prol de conformar adequadamente a proteção dos bens jurídicos envolvidos, de modo a continuar considerando a incidência da vontade do paciente nos processos relacionados ao fim de sua existência.

PALAVRAS-CHAVE: Diretivas antecipadas de vontade; Autonomia dos melhores interesses; Bioética principialista; Alteridade.

\section{MEDICAL PRACTICE AND ADVANCED DIRECTIVES: AN ETHICAL AND JURIDICAL ANALYSIS OF HARMONIC CONFORMATION BET WEEN AUTONOMY AND OTHERNESS}

ABSTRACT: Adequate conformation practice in medicine with regard to autonomy models of advanced directives procedures, also known as Living Will, and otherness, is analyzed. The autonomy of the best interests, acknowledged by the bioethics

\footnotetext{
Doutora em Relações Sociais e Novos Direitos pela Universidade Federal da Bahia (UFBA); Docente da Universidade Católica do Salvador (UCSal), da Universidade do Estado da Bahia (UNEB) e da Faculdade Baiana de Direito, Brasil. E-mail: anatherezameirelles@gmail.com

** Doutora em Direito das Relações Sociais PUC/SP; Docente da Universidade Católica do Salvador (UCSal) e da Universidade Federal da Bahia (UFBA), Brasil.
} 
proposal, may be implemented by the doctor's deciding capacity which meets the patient's perspective, but must also be based on the principles of otherness. A clear design of the medical decision is delineated to conform adequately to the protection of the legal items involved, so that the patients' will in the processes related to their existence is taken into account.

KEY WORDS: Advanced directives; Autonomy of the best interests; Bioethics; Otherness.

\section{PRÁCTICA MÉDICA Y DIRECTIVAS ANTICIPADAS DE VOLUNTAD: UN ANÁLISIS ÉTICO-JURÍDICO DE LA CONFORMACIÓN HARMÓNICA ENTRE LOS PRESUPUESTOS AUTONOMÍA Y ALTERIDAD}

RESUMEN: Artículo destinado a la avaluación de la adecuada conformación práctica de la actuación médica considerando los modelos de autonomía pertinentes al procedimiento de las Directivas Anticipadas de Voluntad, conocidas también como Testamento Vital, y el presupuesto de la alteridad. La autonomía de los mejores intereses, reconocida por la propuesta de la bioética principialista, puede ser consubstanciada por el ejercicio de la capacidad decisoria del médico, que puede ir al encuentro a la perspectiva decisoria deseada por el paciente, por lo debe ser basada en el horizonte propuesto por el sentido de alteridad. Se tiene como objetivo el delineamiento claro de la medida de actuación de la decisión médica en favor de conformar adecuadamente la protección de los bienes jurídicos involucrados, de modo a continuar considerando la incidencia de la voluntad del paciente en los procesos relacionados al fin de su existencia.

PALABRAS CLAVE: Directivas Anticipadas de Voluntad; Autonomía de los mejores intereses; Bioética principialista; Alteridad.

\section{INTRODUÇÃO}

As situações existenciais sempre motivaram um plexo significativo de temas jurídicos por estarem visivelmente assentadas na necessidade de avaliar a medida adequada de incidência da autonomia privada. Tal medida jamais estaria delineada pela Ordem Jurídica, já que falar do exercício de um "direito à autonomia" tem como pressuposto um ato construtivo. O direito recepciona a autonomia, dando-lhe caráter fundamental, mas não contigencia o seu exercício e não aponta diretrizes 
claras para que se possa estabelecer uma dicotomia entre as situações onde será admitido o pleno exercício das liberdades individuais e as situações de cerceamento de tal liberdade, justificadas por um juízo de indisponibilidade que tradicionalmente recai sobre determinados direitos.

Assim são os temas da bioética que resvalam para a perspectiva jurídica. Qualquer construção argumentativa, seja histórica, científica ou metafísica, apontará para o problema da admissibilidade do exercício da autonomia por meio de decisões que possam não reproduzir juízos tradicionais ou mesmo majoritários. A admissibilidade de que a autonomia possa ser um veio condutor para solver situações existenciais que se concretizam a partir da dor e do sofrimento humanos é uma possibilidade ainda ascendente na trajetória das ordens jurídicas em geral.

O fim da existência do ser humano pode agregar uma série de situações difíceis, a começar pela necessidade de compreensão dos procedimentos médicos, motivados por um juízo social de que compete ao profissional dizer, sem sombra de dúvidas, o que é melhor para o seu paciente. Longe de contestar a essência da atividade médica e a própria histórica do sentido da existência da medicina, a questão não é tão simples como parece. A decisão pelo uso de determinados medicamentos e a manutenção de procedimentos ou tratamentos terapêuticos não é um caminho a ser construído apenas pelo argumento técnico, mas também pelo argumento da individualidade, do afeto, da compaixão e dos sentimentos que motivam a garantia da participação do paciente e/ou dos seus familiares no processo de instauração da morte.

A problemática proposta no artigo parte justamente da necessidade de conformar o exercício da prática médica, revelada pelo sentido do modelo bioético da autonomia dos melhores interesses, às demandas do paciente, sem que isso avilte os pressupostos éticos e jurídicos que condicionam o exercício da vontade (por meio das diretivas antecipadas de vontade). O problema parte da necessidade de que a opinião médica e a vontade do paciente (compreendida a partir do argumento da alteridade, que possibilita melhor compreensão da ideia de sofrimento e dor) possam encontrar uma medida exata de harmonia.

$\mathrm{O}$ artigo tem como objetivo geral promover uma análise da conformação adequada entre os pressupostos "autonomia do médico" e "autonomia do paciente" (alcançada pelo sentido de alteridade) na busca da harmonização que possibilite uma justa convivência. Tem ainda como objetivos específicos avaliar como o modelo 
bioético principialista da autonomia dos melhores interesses está diretamente relacionado à prática médica e apontar algumas diretrizes importantes que devem ser observadas durante a conformação de tal atuação técnica. A partir da identificação das decisões que podem competir ao profissional da medicina, estabelece-se reflexão em torno da conformação desse agir médico com a garantia do exercício da autonomia do enfermo, que pode vir modelada pela perspectiva pura ou substituta, conforme a matriz principialista e também pode ser fundamentada na proposta emanada do sentido de alteridade.

A pesquisa tem como caminho metodológico a perspectiva dedutiva, que identifica as premissas importantes a serem consideradas, emanadas, em essência, dos conteúdos normativos ético-jurídicos, para, a partir daí, estabelecer interpretação e dedução adequada consoante à proposta do problema. Como fontes utilizadas ao longo do texto, têm-se livros, capítulos em obras coletivas e artigos em periódicos nacionais e estrangeiras, bem como resoluções e legislações específicas.

\section{A COMPLEXA SITUAÇÃO DA FINITUDE DA VIDA HUMANA}

Dentre todos os direitos consagrados pelas múltiplas ordens jurídicas vigentes, o direito à vida goza de interessantes desdobramentos e potenciais complexidades. Não apenas pela condição de pressuposto aos demais direitos, mas, por dois outros motivos, pela difícil explicação em torno de sua origem (e do mandamus que determinou de fato o começo de sua existência) e pela crescente dificuldade em hamornizá-lo com outros direitos emergentes, relacionados, sempre, à expressão da individualidade humana, externada por distintas perspectivas culturais e valorativas.

A vida é, pois, o mais desafiador dos direitos, quando reclama a determinação precisa dessa proteção, quando demanda da sociedade e dos operadores do direito a realização de sua tutela e quando enfrenta outros direitos com expressividade crescente e imediata, relacionados em essência à dignidade humana, elemento que evidencia a necessidade de proteção do ser humano por sua condição ontológica.

$\mathrm{O}$ espectro desse desafio torna-se evidente nas situações que envolvem as decisões relacionadas ao começo, à continuidade e ao fim da vida.

A discussão em torno do exercício da autonomia perante a continuidade da 
própria existência não está unicamente contingenciada pela constatação de estados terminais. A pluralidade humana, em suas múltiplas dimensões, aponta para discutir também a possibilidade de que, mesmo diante de doenças graves que expressem estados não terminais, as pessoas decidam por não quererem continuar vivendo, motivadas por convicções pessoais variadas. Uma doença não necessariamente terminal, mas o suficientemente sofrível pode, por exemplo, tornar-se a motivação para que alguém deseje a própria morte.

Entretanto, também não se pode negar que a discussão em torno do morrer com dignidade esteve e continua expressivamente ligada aos casos que apontam, por meio de uma leitura médica, para um estado tecnicamente terminal. O número acentuado de pessoas no mundo que terminam a vida num leito de hospital vivenciando um delicado processo de morte, durante dias, semanas ou meses, tem aumentado. Ao lado desse aumento, eclodiu a necessidade de pensar a assistência ao processo de morte, motivada pela diminuição do sofrimento e da dor que podem acometer os indivíduos ao final das suas vidas. Na prática, buscou-se a propagação da ideia de que as pessoas são titulares do direito de morrer dignamente e, em teoria, passou-se ao desafio em torno da busca por preencher o conceito de morte digna.

Alguns elementos se tornaramfulcrais paraoalcance deste propósito, de modo que "the definition of "dying with dignity" recognizes the intrinsic, unconditional quality of buman worth but also external qualities of physical comfort, autonomy, meaning fulness, preparedness, and interpersonal connection" ${ }^{\prime 3}$. A compreensão do que é morrer com dignidade perpassa então por elementos pessoais, conectados por aspectos espirituais, não científicos e que refletem concepções, estilo ou motivações de vida distinto, dificilmente compreendidos por um juízo uníssono, mas, sim, plúrimo, polissêmico e explicado pelo sentido de relativização. O processo de morte também é um processo relativo, cuja condução reflete uma percepção de vida que não se comunica unissonamente e está associado à proposta democrática de respeito às liberdades individuais.

A noção sobre finitude pode ser captada pela proposta de Fermim Schramm, tendo como base o fato de que, quando se pensa em finitude, deve-se ter em voga

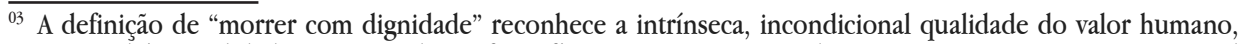
mas também qualidades externas de conforto físico, autonomia, sentido, preparação e conexão interpessoal (Tradução livre). Cf. COOK, Deborah; GRAEME ROCKER. Dying with Dignity in the Intensive Care Unit. The new England Journal of Medicine. June 26, 2014, p. 2506.
} 
que este substantivo representa uma espécie de neologismo originado na língua inglesa durante o século XVII, captado pelo sentido de "caráter daquilo que é finito", representando uma propriedade do que é limitado no tempo e no espaço, e, ao mesmo tempo, simbolizando a condição humana em sua ontológica realidade: a partir de uma perspectiva limitada ou finita. Não se pode ignorar que, do ponto de vista conceitual, o que é finito deve ser percebido a partir de uma correlação direta com o que é infinito, somente assim será possível delimitar dialeticamente a compreensão da ideia em torno do finito ${ }^{04}$.

A percepção sobre o processo de nossa própria finitude pode ser iniciada quando presente o adoecimento, quando instaurado um diagnóstico que possa estar relacionado a indícios de patologia incurável e/ou evolutiva. A finitude, para o ser humano, mantém nítida associação à ideia de perda de saúde, ainda que se registre que o fim pode ser furtivo ou superveniente, decorrente, por exemplo, de um mal súbito ou de um acidente.

A finitude, mesmo que parte da realidade da vida humana, exara teor expressivo de complexidade porque é um problema de natureza filosófica, não estando, pois, facilmente ao alcance dos nossos pensamentos diários. O humano, por vezes, foge ao pensamento sobre a finitude da sua própria vida como uma estratégia confortável e anticonflitiva e, quando o faz, procura associá-lo a explicações metafísicas, espirituais e gnosiológicas.

A complexa situação da finitude da vida humana é explicada pelos diversos elementos que compóem as circunstâncias da despedida da vida, desde aqueles que se relacionam aos aspectos não racionais, aos que podem ser discutidos a partir do espectro da racionalidade, como a conformação do exercício das convicções pessoais, motivado pelo atributo da autonomia, em torno do processo de morte. As decisões em torno do morrer representam a consciente administração das circuntâncias dessa finitude e possuem motivação ontológica clara advinda dos valores humanos, expressos em princípios éticos e jurídicos.

\section{AS DIRETIVAS ANTECIPADAS DE VONTADE NO DIREITO BRASILEIRO}

${ }^{04}$ SCHRAMM, Fermim Roland. Finitude e Bioética do Fim da vida. Revista Brasileira de Cancerologia, 2012, 58(1). Disponível em: < http://www.inca.gov.br/rbc/n_58/v01/pdf/1artigoopinicaofinitudebioeticafim vida. pdf >. Acesso em: 23 fev. 2017, p.73. 
O reconhecimento da possibilidade de exercício da vontade para escolher tratamentos e/ou procedimentos que possam ser adotados quando instaurado o processo de fim da vida tornou-se importante paradigma corroborador dos efeitos práticos da admissibilidade da incidência da autonomia nas situações existenciais.

A possibilidade de que o direito de recusa passasse a ser admitido veio acompanhada da dificuldade de observância da clareza necessária à delicadeza do assunto. A questão está cingida à disciplina conferida por normativa de classe, emanada da resolução 1995/2012 ${ }^{05}$ do Conselho Federal de Medicina, e demanda esclarecimentos indispensáveis, tanto conteudísticos, relacionados às circunstâncias pertinentes à recusa, quanto procedimentais, referentes aos aspectos formais da externalização da vontade. Acrescente-se que em outros países Diretivas Antecipadas de Vontade são conhecidas também como Testamento Vital e Instruções Prévias, fugindo à proposta deste artigo o estudo detalhado que possa motivar os diferentes conceitos.

O reconhecimento do direito de recusa à submissão a tratamentos atinentes ao fim da vida é um movimento expansivo e global, já nitidamente externado por alguns países e que ultrapassa a fronteira estabelecida historicamente do caráter absoluto ou da total indisponibilidade do direito à vida. Países europeus, como Holanda e Bélgica, adotaram caminhos legais para o reconhecimento pleno da autonomia dos pacientes terminais para decidir sobre a sua própria morte. No mesmo sentido, recentemente, o Estado americano de Oregon, que reforçou a admissibilidade de procedimentos, e a Espanha, que manifestou tímidos avanços

05 "RESOLVE: Art. $1^{\circ}$ Definir diretivas antecipadas de vontade como o conjunto de desejos, prévia e expressamente manifestados pelo paciente, sobre cuidados e tratamentos que quer, ou não, receber no momento em que estiver incapacitado de expressar, livre e autonomamente, sua vontade.

Art. $2^{\circ}$ Nas decisões sobre cuidados e tratamentos de pacientes que se encontram incapazes de comunicar-se, ou de expressar de maneira livre e independente suas vontades, o médico levará em consideração suas diretivas antecipadas de vontade.

$\S 1^{\circ}$ Caso o paciente tenha designado um representante para tal fim, suas informações serão levadas em consideração pelo médico.

$\S 2^{\circ} \mathrm{O}$ médico deixará de levar em consideração as diretivas antecipadas de vontade do paciente ou representante que, em sua análise, estiverem em desacordo com os preceitos ditados pelo Código de Ética Médica.

$\S 3^{\circ}$ As diretivas antecipadas do paciente prevalecerão sobre qualquer outro parecer não médico, inclusive sobre os desejos dos familiares.

$\S 4^{\circ} \mathrm{O}$ médico registrará, no prontuário, as diretivas antecipadas de vontade que lhes foram diretamente comunicadas pelo paciente.

$\S 5^{\circ}$ Não sendo conhecidas as diretivas antecipadas de vontade do paciente, nem havendo representante designado, familiares disponíveis ou falta de consenso entre estes, o médico recorrerá ao Comitê de Bioética da instituição, caso exista, ou, na falta deste, à Comissão de Ética Médica do hospital ou ao Conselho Regional e Federal de Medicina para fundamentar sua decisão sobre conflitos éticos, quando entender esta medida necessária e conveniente". (CONSELHO FEDERAL DE MEDICINA. Resolução 1995/2012. Dispõe sobre as diretivas antecipadas de vontade dos pacientes. Disponível em: < http://www.portalmedico.org.br/resolucoes/ CFM/2012/ 1995_2012.pdf>. Acesso em: 25f ev. 2017). 
legais sobre a autonomia do paciente em final da vida ${ }^{06}$.

\subsection{NOÇÕES ELEMENTARES SOBRE AUTONOMIA}

A admissibilidade da manifestação de vontade em situações que envolvem o fim da vida para fins de condução dos protocolos nas unidades intensivas de tratamento pressupõe a compreensão evolutiva da ascensão do argumento da autonomia privada dentro da Ordem Jurídica. A vontade para o direito, em tempo pretérito, era emimentemente geradora de imediatos efeitos jurídicos, quando objetivamente considerada a partir da ótica do liberalismo. A autonomia, antes denominada autonomia da vontade, representava a expressão admitida da intenção humana desassociada de limites jurídicos bem delineados.

A modernidade introduziu o conceito de autonomia como foco central das especulações teóricas e imputou à perspectiva kantiana a concepção de autonomia a partir de uma reflexão filosófica, o que culminou no seu deslocamento para o discurso jurídico. Através do imperativo categórico de Kant, em que se observou a relevância do reconhecimento do homem como fim em si mesmo, passou-se a admitir a autonomia como um pressuposto indispensável à orientação das ações em torno das relações sociais ${ }^{07}$.

A autonomia, como um pressuposto que deve ser reconhecido a todo indivíduo, promove o alcance da razão humana comum com o objetivo de se identificar o que é um dever consistente e um dever inconsistente, ou seja, qual caminho é o melhor na tomada de todo processo decisório ${ }^{08}$.

A autonomia e a liberdade estão essencialmente vinculadas na construção de Kant. "Ser autônomo é ser livre no sentido moralmente relevante, e a liberdade moral se expressa ou se torna evidente na ação autônoma". Ao ampliar o conceito de autonomia para a esfera pessoal, Kant propugnava que a razão prática humana é expressada pela lei do imperativo categórico, que deve conduzir nossos desejos, sentimentos e modo de conceber a vida, e a moralidade do ser humano, então, é o

06 DURÁN, Maria Ángeles. La calidad de muerte como componente de la calidad de vida. Revista Españhola de Investigaciones Sociológicas. Disponível em: <http://www.reis.cis.es/REIS/PDF/ REIS106031167998092686pdf> . Acesso em: 25 fev. 2017, p.11.

${ }^{07}$ MOUREIRA, Diogo Luna. O reconhecimento e a legitimação da autonomia privada aplicada ao Biodireito. Anais, Conpedi. Disponível em: <www.conpedi.org.br/manaus/arquivos > . Acesso em: 02 ago. 2014, p.102.

${ }^{08}$ SCHNEEWIND, Jerome B. A invenção da autonomia. Tradução de Magda França Lopes. São Leopoldo: Unisinos, 2005, p.560. 
resultado do seu livre arbítrio ${ }^{09}$.

O conceito de autonomia de matriz kantiana não se confunde com a autonomia em sentido jurídico, trabalhada hodiernamente na construção dogmática do direito civil contemporâneo. Em termos bioéticos, a autonomia está relacionada diretamente à necessidade de respeito às decisões individuais no decorrer dos processos médicos e biocientíficos. A bioética principialista buscou detalhar o seu contorno, identificando suas bases fundantes.

O importante papel dos dois objetivos fundamentais da República, previstos na Constituição (garantia do pluralismo e tutela da dignidade da pessoa humana), é corolário da busca pela configuração adequada da autonomia privada. Uma Constituição democrática que recepciona o pluralismo não se restringue à aplicação das regras da maioria, respeita os desejos da minoria por reconhecer a relevância da pessoalidade ${ }^{10}$. Os objetivos e fundamentos da República coadunam uma cultura heterogênea, porque recepcionam o multiculturalismo, que, ao abraçar a diferença como realidade, "ultrapassa a especificidade de qualquer contexto nacional e propõe um sério desafio de civilização às sociedades contemporâneas"11.

Pensar de modo contrário à perspectiva multicultural significa reforçar o argumento do paternalismo, que contraria a tendência já evidente da ascensão das liberdades individuais. A existência humana não pode mais ser concebida se contingenciada pela interferência injustificada do Estado em situações privadas e concernentes à realização da dignidade existencial humana. As manifestações heterônomas, pautadas em aspectos genéricos, majoritários, que não consideram a individualidade, são percebidas em interferências normativas abusivas, fruto de imposições culturais e morais. "A construção autônoma dessas escolhas é que acarreta legitimidade das mesmas, pois, em matéria de tanta intimidade e de construção da vida privada, não é possível conceber-se imposições heterônomas, mesmo que venham do Estado ou do legislador"12.

A autonomia, juridicamente considerada, é a consequência da evolução dos Estados modernos e fruto de uma perspectiva exarada de uma ordem mundial, cuja recomendação emana de declarações e tratados internacionais. A proposta filosófica é o embrião do sentido ontológico da autonomia e contributo fundamental para

\footnotetext{
${ }^{09}$ Idem. Kant e a moralidade como resultado de nossa autonomia. Revista do Instituto Humanistas Unisinos, São Leopoldo, 417, ano XIII, 2013, p.1.

${ }^{10}$ TEIXEIRA, Ana Carolina Brochado. Saúde, corpo e autonomia privada. Rio de Janeiro: Renovar, 2010, p.92-93.

${ }^{11}$ SEMPRINI, Andrea. Multiculturalismo. Tradução de Laureano Pelegrin. Bauru, SP: EDUSC, 1999, p.9.

${ }^{12}$ SEMPRINI, Andrea. Multiculturalismo. Tradução de Laureano Pelegrin. Bauru, SP: EDUSC, 1999, p.180.
} 
uma compreensão para além do aspecto técnico do que é ser de fato um agente autônomo. Certo é que a autonomia é essencialmente elementar, porque é o atributo propiciador do descontigenciamento e da libertação do ser humano.

\subsection{O PRESSUPOSTO DA ORTOTANÁSIA}

As discussões em torno da possibilidade de qualquer atuação médica no processo de morte do paciente, no Brasil, partem da ausente submissão da questão ao processo legislativo ordinário e da normatização classista do Conselho Federal de Medicina por meio da resolução 1.805 do ano de 2006.

A mesma, em seu artigo $1^{\circ}$, determina que "é permitido ao médico limitar ou suspender procedimentos e tratamentos que prolonguem a vida do doente em fase terminal, de enfermidade grave e incurável, respeitada a vontade da pessoa ou de seu representante legal." ${ }^{13}$ A resolução, então, já submetida a juízo de legalidade, e tendo permanecido na Ordem Jurídica, emite comando permissivo no sentido de que o médico possa, ouvido o paciente ou quem o represente, suspender tratamentos ou procedimentos inúteis, desde que o doente esteja em situação terminal e porte uma doença grave e incurável.

Emergem do demonstrado conteúdo normativo a dificuldade de apurar dois conceitos importantes: estado de terminalidade e doença grave e incurável.

A resolução determina ainda que cabe ao médico esclarecer ao doente ou a seu representante legal quais são as modalidades terapêuticas adequadas para cada situação, registrando que o mesmo continuará a receber todos os cuidados necessários para aliviar os sintomas que levam ao seu sofrimento, garantida a sua assistência integral, o seu conforto físico, psíquico, social e espiritual, que inclui inclusive o direito da alta hospitalar.

A proposta que recepciona a legitimidade e a legalidade da conduta ortotanásia não tem como pressuposto o abandono do paciente à sua própria morte, submetendo-o ao desassistencialismo ou à inércia de qualquer intervenção médica. A ortotanásia caminha com a necessidade de manutenção de cuidados paliativos, que contribuem para o aumento da margem de conforto do paciente.

A compreensão sobre o procedimento ortotanásico está associada à apropriação dos distintos estados clínicos dos pacientes. Tradicionalmente, a 
suspensão ou a omissão de tratamentos sempre esteve associada à constatação do estado terminal, mas, hoje, a discussão tem demandado reflexões em torno de outras hipóteses clínicas, que não configuram, de fato, situações de terminalidade.

O conceito de terminalidade não representa para a ciência médica um juízo único. Pode-se pensar que um paciente terminal é aquele "cuja condição é irreversível, independentemente de ser tratado ou não, e que apresenta uma alta probabilidade de morrer num período relativamente curto de tempo"14. A configuração do estado de terminalidade está, dentro da medicina, majoritariamente, associada a dois elementos: a existência de uma patologia incurável e a iminência da morte. A questão ganha argumentos mais complexos quando se verifica que a discussão alcançou as situações onde há apenas a patologia ou doença incurável, dispensando o pré-requisito da morte iminente. Algumas situações evidenciam o inexistente lapso curto de tempo de sobrevida, tratando-se de casos em que o paciente é portador de uma doença que não tem cura e atinge, de maneira substancial, a sua qualidade de vida.

Outros estados clínicos passaram a integrar o rol das situações nas quais se discute o exercício do direito de recusa a tratamentos médicos e tal pressuposto tem agravado a dificuldade em uniformizar um entendimento legítimo.

Uma das situações discutidas parte das lesões ao sistema nervoso central que comprometem de forma diversa o normal funcionamento do cérebro. Independentemente da causa da lesão, pode surgir um quadro de coma, que pode evoluir de várias formas. Nos extremos, estarão a recuperação completa do paciente ou a morte cerebral, mas entre eles estão situações de gravidades diferentes e de prognósticos distintos, entre as quais o estado vegetativo persistente (EVP) ${ }^{15}$.

A definição de estado vegetativo persistente foi apontada num estudo estabelecido pela Multi-Society Task Force no relatório de 1994. O estado vegetativo é uma "situação clínica de completa ausência da consciência de si e do ambiente circundante, com ciclos de sono-vigília e preservação completa ou parcial das funções hipotalâmicas e do tronco cerebral". Os critérios que evidenciam a constatação do estado são a total ausência de consciência do si ou do ambiente externo; a impossibilidade de interação; a ausência de respostas intencionais

\footnotetext{
${ }^{14}$ KNOBEL, Marcos; SILVA, Ana Lúcia Martins. O paciente terminal: vale a pena investir no tratamento? Einstein. São Paulo, 2004, v.2, p.133.

${ }^{15}$ CARNEIRO, António Vaz; ANTUNES, João Lobo; FREITAS, António Falcão de. Conselho Nacional De Ética Para as Ciências da Vida. Relatório sobre o Estado Vegetativo Persistente. Portugal, 2005. Disponível em: <www. cnecv.pt/admin/files/data/docs/1273055807_P045_RelatorioEVP.pdf > . Acesso em: 25 fev. 2017, p.2.
} 
e voluntárias a estímulos visuais, auditivos e táteis; a ausência da capacidade de compreensão ou expressão verbal; a vigília intermitente, associada a ciclos sonovigília; a preservação das funções hipotalâmicas e autonômicas suficientes para a sobrevivência; a incontinência urinária e fecal; bem como a preservação em grau variável dos reflexos dos nervos cranianos (como as pupilares, óculo-vestibulares e de deglutição) ${ }^{16}$.

Pode-se inferir que o estado vegetativo persistente não implica no estado necessariamente terminal, mas, de igual modo, têm suscitado discussões em torno da possibilidade de atendimento à decisão de recusa quando previamente manifestada pelo paciente.

Do mesmo modo, discute-se a admissibilidade de tal manifestação quando identificado o quadro de demência avançada, consequência da evolução de determinada doença. A demência avançada pode ser definida como uma "síndrome caracterizada por declínio de memória associado a déficit de pelo menos uma outra função cognitiva (linguagem, gnosias, praxias ou funções executivas) com intensidade suficiente para interferir no desempenho social ou profissional do indivíduo. ${ }^{17 "}$

A recusa aos tratamentos médicos em sede de prática ortotanásica está cingida, conforme a resolução do Conselho Federal de Medicina, aos estados terminais, mas, a discussão é evidentemente alargada para outras possibilidades. Sabe-se que historicamente a demência avançada não configura um estado clínico onde há possibilidade de recusa a tratamento médico, mas, pode-se perceber a necessidade de repensar a restrição às situações de terminalidade, tendo em vista que estas não abrangem, em totalidade, as demandas sociais emergentes.

A conduta ortotanásica parte da avaliação da situação concreta do paciente, buscando identificar se a medida, o tratamento ou o procedimento usado para a manutenção da vida do mesmo tem natureza proporcional, útil, necessária e ordinária. A análise tem como ponto de partida a verificação do grau de essencialidade da medida mantida ao paciente, para que se possa, a partir de uma análise técnica, feita pelo profissional habilitado, concluir sobre a manutenção ou sobre a suspensão do procedimento.

A natureza ordinária de um tratamento de manutenção de vida se explica

\footnotetext{
${ }^{16}$ Ibidem, p.3.
}

${ }^{17}$ CARAMELLI, Paulo; TONIDANDEL, Maira. Como dialgnosticar as quatro causas Como diagnosticar as quatro causas mais freqüentes de demência? Revista Brasileira de Psiquiatria, 2002;24, Supl. I, p. 7. 
pelo seu grau de disponibilidade e acessibilidade, pelo seu baixo custo e pouca agressividade, já que são aceitos comumente como cuidados básicos aos pacientes em estado grave. Os extraordinários são cuidados mais específicos, dispendiosos e que agregam riscos e limites de uso. As medidas proporcionais evidenciam utilização sistemática e obrigatória por representarem benefício ao paciente, de modo que as desproporcionais são optativas e representam aspectos negativos que superam as perspectivas favoráveis ${ }^{18}$.

Um tratamento pode ser considerado fútil quando não consegue oferecer benefício real a um paciente, pois a sua morte é inevitável, e representa, portanto, nenhuma possibilidade de beneficência ao quadro clínico instaurado. Essa noção de utilidade (desdobrada para outros autores como noções de necessidade, proporcionalidade e ordinariedade) não é suficiente para resolver, de maneira adequada, todas as situações concernentes à discussão em voga, já que é genérica e pouco considera o caso concreto.

Alguns exemplos ilustram a necessária observância da situação em concreto, como a análise da natureza do procedimento de hemodiálise em pacientes com insuficiência real transitória ou definitiva. A insuficiência real pode ser tratamento ordinário e necessário a determinado paciente, mas se torna fútil e desproporcional quando medida insistente em caso de comprometimento irreversível e definitivo do sistema renal ${ }^{19}$.

A configuração de futilidade a ser imputada a um tratamento é uma tarefa de difícil juízo, demandando em cada caso esclarecer qual é o sentido que se está dando ao termo: o sentido denotativo da noção de efetividade de um tratamento ou o sentido conotativo que emite o juízo de valor revelado como algo positivo ou negativo do ponto de vista ético. Estabelecer esse juízo, seja qual for o sentido escolhido, é tarefa difícil por envolver posicionamentos antagônicos e conflitos decorrentes do poder de decisão do paciente, da família e do médico ${ }^{20}$.

A manutenção dos cuidados paliativos é obrigatória em caso de constatação dos estados de terminalidade, independentemente da decisão sobre a prática da ortotanásia.

A introdução de cuidados paliativos pode reduzir a angústia causada pelos

\footnotetext{
${ }^{18}$ VILLAS-BÔAS, Maria Elisa. Da eutanásia ao prolongamento artificial. Aspectos polêmicos na disciplina jurídicopenal do final da vida. Rio de Janeiro: Forense, 2005, p;48-49.

${ }^{19}$ GARAY, Oscar. Derechos fundamentales de los pacientes. Buenos Aires: Ad-Hoc, 2003.

${ }^{20}$ SCHRAMM, Fermim; FLORIANI, Ciro Augusto. Cuidados paliativos: interfaces, conflitos e necessidades. Ciência \& Saúde Coletiva, 13, (Sup 2), 2008, p.2125.
} 
sintomas e melhorar a qualidade de vida dos pacientes perto do fim da vida. No entanto, cresce a evidência de que é incipiente atualmente o número de especialistas em cuidados paliativos. Projeta-se um cenário de médicos especialistas em segmentos técnicos da medicina, sem que os mesmos conheçam, em essência, o significado da paliação. Na verdade, a responsabilidade de assegurar bons cuidados de fim de vida aos pacientes caminha para continuar recaindo para especialistas em áreas que não se preocuparam em compreender ou a estudar tais cuidados. Assim, a familiaridade com medidas básicas de conforto deveria ser uma habilidade essencial para todos clínicos que cuidam de pacientes cuja morte é iminente, ou seja, tal capacidade de cuidado deveria ser inerente à quase todas as áreas de especialidade ${ }^{21}$.

Cumpre o registro de que o caminho sugerido por esta pesquisa não assenta na passagem da prática da eutanásia ao juízo de permissibilidade, mas no preenchimento adequado e justo do próprio sentido de ortotanásia, ontologicamente conduzida pela necessidade de preservação dos valores de piedade e compaixão sem dispensar a observância de limites determinados.

\section{A ATUAÇÃO MÉDICA EM FACE DOS MODELOS DE AUTONOMIA}

O exercício da autonomia, diante das múltiplas situações complexas relacionadas à contingência do simples fato de ser um humano, é revelador de expressivos conflitos de moralidade. O próprio sentido a ser reconhecido no conceito de autonomia pode emanar espectros morais distintos, ou seja, denotar coeficientes culturais fincados em convicções de ordem individual difíceis de harmonização ou convivência. As pessoas são, pois, diferentes moralmente e por isso podem expressar decisões morais distanciadas ou estranhas entre si.

A concretização dessa autonomia pode muitas vezes restar obstada por barreiras de fundo moral, reveladas por meio de limites emanados de recomendações éticas ou normas jurídicas. É necessário compreender em que medida a autonomia decisória do ser humano deve sofrer limitações e quais são elas, esmiuçando as motivações que as justificam para que as mesmas desfrutem de legitimidade.

${ }^{21}$ Cf. BLINDERMAN, Craig D.; ANDREW BILLINGS, J. Comfort Care for Patients Dying in the Hospital. The new england journal of medicine. December 24, 2015, p. 2549. 
Há de se firmar o pressuposto de que ao ser humano deve ser reconhecida a prerrogativa de poder exercer a sua autonomia, única saída para os Estados democráticos cujo regime político esteja fincado no valor da pessoa humana. A ideia da autonomia é, antes de tudo, ontologicamente anterior ao Sistema Jurídico, se vista como um pressuposto inerente à condição da humanidade. A condição humana é eminentemente autônoma, de modo que o atributo da racionalidade conduz, quase que naturalmente, à capacidade de autonomia.

\subsection{A INCIDÊNCIA DOS MODELOS}

As relações entre médicos e pacientes são naturalmente consolidadas pela manifestação do consentimento, que se reduz à assinatura de um termo, tradicionalmente conhecido como Termo de Consentimento Livre e Esclarecido (TCLE). A autonomia então é manifesta a partir de uma expressão direta da vontade do paciente, que é o responsável por ler, compreender, preencher e assinar este documento. No entanto, nem sempre quem assina o termo de consentimento compreendeu adequadamente e/ou em totalidade todas as informações prestadas no instrumento. A compreensão então pode passar a ser técnica e automática e longe de um alcance cognitivo ideal.

A não compreensão adequada do conteúdo reduzido a termo é um problema persistente no âmbito da reflexão bioético-jurídica. O exercício da autonomia reconhecido pelo direito está tradicionalmente associado à perspectiva de alcance da capacidade, por isso, as razões subjetivas que evidenciam que nem todo sujeito normativamente capaz é manifestamente autônomo para exercer determinadas decisões terminam não sendo contempladas pela ótica jurídica. A compreensão de todos os pressupostos, revelados por meios de riscos, efeitos colaterais, consequências, recomendações terapêuticas e outros, nem sempre é alcançada pelo sujeito civilmente capaz.

A controvérsia esmiuçada é disciplinada pela bioética principialista, na medida em que a mesma aponta para a necessária distinção entre pessoas autônomas e ações autônomas. Uma ação colimada de autonomia deverá reunir indispensavelmente três pressupostos, a ação deve ser manifestamente intencional, 
deve pressupor a compreensão das informações em totalidade e deve estar livre de influências ${ }^{22}$. O agir autônomo, então, está longe de ser definido pelo ângulo da capacidade civil, por exigir a presença de elementos subjetivos, concebidos como indispensáveis, que legitimam o exercício de decidir.

A concepção de autonomia numa perspectiva bioética desloca-se para uma abordagem aplicada, na medida em que considera a situação pessoal do agente manifestante da vontade, avaliando-o, inclusive, sob o manto da vulnerabilidade diante da relação em que deva manifestar consentimento. Hoje, é possível perceber que são nítidos os avanços em torno da preocupação do direito com os contextos de vulnerabilidade contingenciados por relações médicas, o que auxilia na reconformação do real conceito de autonomia pertinente às situações que envolvem tais contratos.

As circunstâncias que integram as decisões atinentes ao final da vida humana devem contar com uma clara e precisa informação prognóstica. Acrescentese ainda que "valid prognostic information is a fundamental component of endof-life discussions. Understanding the predicted outcome of the critical illness and recognizing the uncertainty of that prediction are belpful in making decisions that reflect the patient's values" ${ }^{23}$.

Beauchamp e Childress ${ }^{24}$ desenvolvem a bioética principialista, analisando o princípio da autonomia partindo de três modelos, o modelo da pura autonomia, o modelo do julgamento substituto e o modelo dos melbores interesses. Pode-se atentar que todos os modelos foram admitidos na resolução 1995/2012 do Conselho

${ }^{22}$ BEAUCHAMP, Tom; CHILDRESS, James. Princípios de Ética Médica. Tradução Luciana Pudenzi. São Paulo: Loyola, 2002.

${ }^{23}$ Informações prognósticas válidas são um componente fundamental das discussões de fim de vida. Entender o resultado previsto da doença crítica e reconhecer a incerteza dessa previsão são úteis na tomada de decisões que refletem os valores do paciente (Tradução livre) Cf. COOK, Deborah; GRAEME ROCKER. Dying with Dignity in the Intensive Care Unit. The New England Journal of Medicine. June 26, 2014, p. 2508.

${ }^{24}$ BEAUCHAMP, Tom; CHILDRESS, James. Princípios de Ética Médica. Tradução Luciana Pudenzi. São Paulo: Loyola, 2002. 
Federal de Medicina ${ }^{25}$, sem que tenha restado clara a conformação dessa incidência. Os modelos imputados tomam como pressuposto a necessária observância da vontade do paciente, caso tenha manifestado, a busca por aquela que seria a sua vontade, caso pudesse manifestar, ou, ainda, a vontade de alguém que possa saber o que é melhor para ele, por meio do julgamento dos melhores interesses.

\subsection{A ADEQUAÇÃO DO EXERCÍCIO DO MODELO DOS MELHORES INTERESSES E O PRESSUPOSTO DA ALTERIDADE}

O modelo dos melhores interesses não pode ser esmiuçado sem a apropriação histórica que permeia o seu entorno. Pensar que cabe exclusivamente ao médico a tomada de decisões relacionadas à vida e à saúde de seu paciente é reconhecer também o pensamento médico-paternalista. Disso não resulta que ao médico não seja devido o reconhecimento da sua função se considerada a sua capacidade técnica, mas é necessário pensar na necessidade de promoção da árdua compreensão do que sejam de fato os melhores interesses de um paciente, para que se possa, ao final, entender se cabe ao profissional da medicina a tarefa de determiná-los em totalidade.

Deve-se ter em voga que "the deliberate overriding of a patient's opportunity to exercise autonomy because of a perceived obligation of beneficence is called paternalism. The word reflects its roots in fatherly or male (paternal) bierarchical

25 "O CONSELHO FEDERAL DE MEDICINA, no uso das atribuições conferidas pela Lei $\mathrm{n}^{\circ} 3.268$, de 30 de setembro de 1957, regulamentada pelo Decreto $\mathrm{n}^{\mathrm{o}} 44.045$, de 19 de julho de 1958 , e pela Lei $\mathrm{n}^{\mathrm{o}} 11.000$, de 15 de dezembro de 2004 [...] RESOLVE: Art. $1^{\circ}$ Definir diretivas antecipadas de vontade como o conjunto de desejos, prévia e expressamente manifestados pelo paciente, sobre cuidados e tratamentos que quer, ou não, receber no momento em que estiver incapacitado de expressar, livre e autonomamente, sua vontade. Art. $2^{\circ}$ Nas decisões sobre cuidados e tratamentos de pacientes que se encontram incapazes de comunicarse, ou de expressar de maneira livre e independente suas vontades, o médico levará em consideração suas diretivas antecipadas de vontade. $\S 1^{\circ}$ Caso o paciente tenha designado um representante para tal fim, suas informações serão levadas em consideração pelo médico. $\S 2^{\circ} \mathrm{O}$ médico deixará de levar em consideração as diretivas antecipadas de vontade do paciente ou representante que, em sua análise, estiverem em desacordo com os preceitos ditados pelo Código de Ética Médica. $\S 3^{\circ}$ As diretivas antecipadas do paciente prevalecerão sobre qualquer outro parecer não médico, inclusive sobre os desejos dos familiares. $\$ 4^{\circ} \mathrm{O}$ médico registrará, no prontuário, as diretivas antecipadas de vontade que lhes foram diretamente comunicadas pelo paciente. $\S 5^{\circ}$ Não sendo conhecidas as diretivas antecipadas de vontade do paciente, nem havendo representante designado, familiares disponíveis ou falta de consenso entre estes, o médico recorrerá ao Comitê de Bioética da instituição, caso exista, ou, na falta deste, à Comissão de Ética Médica do hospital ou ao Conselho Regional e Federal de Medicina para fundamentar sua decisão sobre conflitos éticos, quando entender esta medida necessária e conveniente. [...]" (CONSELHO FEDERAL DE MEDICINA. Resolução 1995/2012. Dispõe sobre as diretivas antecipadas de vontade dos pacientes. Disponível em: < http://www.portalmedico.org.br/resolucoes/ CFM/2012/1995_2012.pdf >. Acesso em: 25f ev. 2017). 
relationships, governance, and care"26. Assim, o argumento da beneficência também precisaria ser repensado, se usado como única mola justificadora para uma tomada de decisão médica. É necessário entender e promover a interação entre a decisão técnica, justificada sob o manto beneficente, e a autonomia do paciente.

Como definir de fato os melhores interesses de um paciente? E quais são esses interesses? O modelo de autonomia em questão não necessariamente esteve associado restritamente à atuação do profissional da medicina, podendo ser compreendido a partir da busca de quais seriam os melhores interesses do paciente, que, também, poderiam ser manifestados e descritos por um membro da família. No entanto, o espectro proposto neste artigo parte justamente da possibilidade de que os melhores interesses de um paciente possam estar preliminarmente associados à decisão do médico ou da equipe que o acompanha, o que justifica a pertinência de uma investigação adequada a respeito da sua incidência.

O modelo dos melhores interesses pressupõe que um decisor substituto deva identificar e determinar o maior benefício dentre as decisões possíveis, a partir de uma análise dos interesses envolvidos do paciente. É uma avaliação que envolve a ponderação entre os custos e os benefícios de determinada escolha, considerando os vários tratamentos ou alternativas de tratamento e a dor e o sofrimento que podem causar o ato decisório. Os melhores interesses de um paciente devem ser aferidos a partir da proposta de manutenção de sua qualidade de vida, que não reflete categoricamente a busca daquilo que ele teria escolhido em um momento possível imaginário ${ }^{27}$.

O modelo não propõe a manutenção da decisão tomada pelo paciente quando era capaz, ou que seja chamado um representante para indicar a provável vontade daquele. O paradigma dos melhores interesses trabalha com a possibilidade de alguém, "normalmente o médico, o Hospital ou uma Comissão, decidir o que considera ser o mais adequado ao paciente, levando em conta parâmetros

${ }^{26}$ A supressão deliberada da oportunidade de exercer a autonomia por causa de uma obrigação concebida como beneficente ao paciente consubstancia o paternalismo. A palavra reflete suas raízes em paternidade ou paternidade hierárquica, relacionamentos, governança e cuidado. (Tradução livre) (RICH, Karen L. Introduction to Bioethics and Ethical Decision Making. In: BUTTS, Janie B.; RICH, Karen L. Nursing Ethics: across the curriculum and into practice. Fourth Edition. Jones \& Bartlett Learning, 2016, p.46).

${ }^{27}$ BEAUCHAMP, Tom; CHILDRESS, James. Princípios de Ética Médica. Tradução Luciana Pudenzi. São Paulo: Loyola, 2002, p. 204-205. 
usualmente observados em circunstâncias semelhantes"28.

A pertinência da recusa elaborada por meio da diretiva pelo paciente deve ser analisada partindo de algumas questões importantes e ainda pouco esclarecidas. Comumente, a possibilidade de recusar tratamentos médicos está socialmente, e diga-se também perante a própria comunidade médica, associada à constatação de um estado avaliado como terminal, ou seja, um estado em que a vida caminha para a morte, como explicado em momento anterior.

Essa restrição da pertinência da diretiva antecipada somente às situações ditas terminais pode consubstanciar uma forma de evidente predominância do modelo dos melhores interesses. A tarefa de dizer quais são as doenças que evidenciam estados terminais e quem está em estado terminal competiria tão somente ao médico, quando, na verdade, deve-se pensar em outras questões a serem consideradas.

A terminalidade justifica, sem dúvidas, a possibilidade de que as pessoas possam manifestar recusas em relação a determinados tratamentos, mas ela não agrega todas as razões que podem motivar o reconhecimento de tal direito, já que a submissão ao direito de recusa ao critério temporal (breve tempo de vida residual) pode não ser sempre benéfica.

A medicina aponta para doenças que podem não ser consideradas terminais, mas comprometem, em essência, a vida dos indivíduos, sendo que, muitas vezes, os tratamentos disponíveis em nada modificam a situação clínica do paciente. Devese pensar que, ainda que o paciente não esteja enquadrado numa dita situação de estado terminal, a manutenção do tratamento de suporte de vida deve deixar de ser obrigatória, uma vez percebida que as desvantagens excedem os benefícios ${ }^{29}$. A dificuldade de preencher o conceito de terminalidade evidencia a necessidade de repensar a pertinência das diretivas, a fim de que o objetivo primordial seja cumprido.

O modelo dos melhores interesses passaria então a contar com o deslocamento da tarefa de determinar quais são as doenças terminais para a tarefa de esclarecer quais são os tratamentos que podem ser considerados inúteis ou

\footnotetext{
${ }^{28}$ AGUIAR, Mônica. Modelos de Autonomia e sua (In)compatibilidade com o Sistema de Capacidade Civil no Ordenamento Positivo Brasileiro: Reflexões sobre a Resolução 1995/2012 do Conselho Federal de Medicina. CONPEDI. Disponível em: < http://www.publicadireito.com.br/artigos/?cod=69c7e73fea7ad35e $>$. Acesso em: 26 fev. 2017, p.8

${ }^{29}$ Cf. BEAUCHAMP, Tom; CHILDRESS, James. Princípios de Ética Médica. Tradução Luciana Pudenzi. São Paulo: Loyola, 2002, p. 238.
} 
desproporcionais àquele paciente. Tal deslocamento culmina na necessidade de atenção aos aspectos seguintes.

Se a diretivas passam a ser pertinentes para além de situações terminais, pode-se entender que seriam pertinentes, por exemplo, em casos de doenças crônicas incuráveis ou enfermidades graves, ressalvando-se o fato de que, perante tais situações clínicas, os tratamentos não sejam mais eficazes, mantendo-se como medidas proteladoras. É caso de paciente em estágio evoluído de esclerose amiotrófica lateral que não necessariamente tenha evoluído para situação de terminalidade. Os tratamentos podem simbolizar inutilidades ao paciente, se, ao serem analisados, não significarem melhora de seu quadro clínico, mas, tão somente, mais dor e sofrimento. A situação de terminalidade evidencia a submissão a um critério temporal, já que terminais são doenças que encurtarão o tempo de vida dos doentes, restrição que pode terminar aumentando a dor e o sofrimento do enfermo.

A proposta é conformar a atuação do médico a um espectro de obediência aos deveres de humanidade. A medicina intensiva tem evidenciado a dificuldade em preencher o conceito de paciente terminal, o que colabora para avaliar se a questão central não estaria na natureza das medidas imprimidas a cada situação em concreto. Há de se considerar dois aspectos extremamente relevantes: a decisão do paciente e/ou da família (seja pelo modelo de autonomia pura ou da substituta) e a avaliação minuciosa dos benefícios dos tratamentos.

Disso resulta a também difícil tarefa em determinar com exaustão e segurança qual é a natureza de tais tratamentos, se são benéficos, portanto, proporcionais, necessários e úteis, ou se são maléficos, por serem desproporcionais, extraordinários e fúteis. Essa é uma ponderação de difícil aferição, mas que demanda o repensar da atuação médica.

A possibilidade de classificar tratamentos médicos como proporcionais e uteis ou desproporcionais e inúteis não pode fugir à regra da avaliação do caso concreto, isto porque se tem como preliminar o afastamento de uma "medicina de evidências". A medicina carece de exatidão por sua própria natureza e tal pressuposto é fácil de ser comprovado contemporaneamente.

O delineamento de uma adequada atuação médica é nitidamente alcançado quando a mesma considera a relevância de "um atuar com alteridade". O pressuposto da alteridade, tradicionalmente concebido pela filosofia como um fator que contribui para a estabilidade e justiça entre os lados de toda relação humana, pode 
justificar o repensar da atuação médica, na medida em que força o deslocamento de perspectiva. A ação pautada na alteridade considera a situação alheia, mobilizandose de maneira condescendente e protetiva perante as circunstâncias vividas por outrem. A reciprocidade, como consequência do atuar com alteridade, implica na apropriação do problema do Outro, ou seja, em perceber, com consciência e afetividade, que o parâmetro para conformar as atuações humanas deve partir da realidade do que o Outro pode estar vivendo.

O Outro, na perspectiva da alteridade, é a "dimensão de desneutralização eminente do Mesmo de si para si mesmo, em meio às suas razões e auto-justificações", e simboliza "o questionamento de toda boa consciência, a saída do ser em excesso e do excesso do ser: um melhor que ser" ${ }^{30}$. A atuação do profissional da medicina, quando pautada no argumento da alteridade, promove o deslocamento da perspectiva individualizada, sempre colimada pelo pressuposto da capacidade técnica, para a perspectiva do paciente. A consciência de um atuar médico a partir dessa proposta pode colaborar para diminuir a assimetria da relação médico-paciente, relação de poder quando encarada à luz da dominação pelo conhecimento.

A capacidade de ver as possibilidades do Outro considerando como próprias possibilidades, saindo de uma perspectiva identitária fechada e aprisionada num universo particular ${ }^{31}$, é tarefa necessária à compreensão da reconformação das relações sociais como um todo. Passa-se então a compreender que esse apropriarse do Outro demanda também um juízo de responsabilidade, natural à atividade médica.

Ao médico deve competir agir com plausibilidade, pautado na medida de consideração da situação clínica, computando a condição do paciente de maneira sistêmica, sem permanecer contingenciado por regras gerais herméticas distanciadas da circunstância vivenciada. Assim, pode-se pensar numa conformação mais adequada do real sentido do modelo dos melhores interesses. A enumeração exaustiva de tratamentos médicos desproporcionais não é capaz de refletir a solução ao problema da admissibilidade das recusas porque se distancia, sem dúvidas, dos primados da alteridade e da compaixão humana.

\footnotetext{
30 SOUZA, Ricardo Timm. Sentido e alteridade: dez ensaios sobre o pensamento de Emmanuel Levinas. Porto Alegre: EDI-PUCRS, 2000, p.62.

${ }^{31}$ LEVINAS, Emmanuel. Entre nós: ensaios sobre a alteridade. Tradução de Pergentino Pivatto. 5.ed. Petrópolis: Vozes, 2010.
} 


\section{CONSIDERAÇÕES FINAIS}

A proposta de conformação das condutas médicas em situações de fim da vida tem como liame conclusivo a reflexão em torno do conceito real de melhor interesse de um paciente. O melhor interesse do enfermo também deve considerar o seu melhor interesse, ou seja, o que ele pensa sobre si mesmo e como pensa a respeito dos procedimentos que podem ser realizados. Este pressuposto é o primeiro aspecto conclusivo que deve ser alinhado à proposta emanada. A decisão do médico em sede de terminalidade não pode ser o argumento capaz de anular em totalidade a necessidade de cumprimento da vontade do paciente, revelada pelas suas diretivas, recepcionada por resolução do Conselho Federal de Medicina, considerada em harmonia com a legislação brasileira.

A proposta não parte da chancela da prática eutanásica, mas, sim, das situações ortotanásicas, em que podem ser dispensados tratamentos médicos fúteis e desnecessários ao paciente, por não alterarem e não beneficiarem seu quadro clínico. A ortotanásia também tem evidenciado margens de dúvidas, na medida em que a medicina não é baseada em evidências e não pode ser concebida como uma ciência exata. Na situação ortotanásica, há de se considerar a reflexão em torno da atuação médica, a partir da construção, junto à autonomia do paciente ou de seu substituto, da melhor solução.

A medicina hermética, compartimentalizada e ainda enraizada por dogmatismos exagerados pode funcionar como mola propulsora à manutenção de entendimentos que podem não ser benéficos aos pacientes. O conceito de doença terminal pode não agregar com suficiência todas as situações que envolvem a existência de uma enfermidade grave e incurável, motivação capaz de justificar a possível admissibilidade de uma decisão autônoma sobre a suspensão de determinados protocolos terapêuticos.

Disso resulta a necessidade de repensar a fórmula pronta da autonomia dos melhores interesses (a que reconhece apenas no médico a capacidade de decidir de maneira adequada), para que a autonomia passe a ser conjunta, passe a ser a consubstanciação construtiva de entendimentos, margeada pela possibilidade de admitir as diretivas antecipadas de vontade.

Cada situação tem, por excelência, um plexo de circuntâncias e motivações que a distingue de outras situações comumentemente conhecidas na literatura 
técnica acessível. A vida do ser humano pode estar colimada de um grau de dor e sofrimento insuportável e este fato é o motivo autorizante para uma atuação médicodecisória justa e proporcional ao que a situação evidencia. Para isso, o médico pode parametrizar sua atuação no argumento da alteridade, perspectiva justa e consciente que propicia a apropriação da delicadeza da situação vivenciada pelo Outro.

\section{REFERÊNCIAS}

BEAUCHAMP, Tom; CHILDRESS, James. Princípios de Ética Médica. Tradução Luciana Pudenzi. São Paulo: Loyola, 2002.

BLINDERMAN, Craig D.; ANDREW BILLINGS, J. Comfort Care for Patients Dying in the Hospital. The new england journal of medicine, dec. 24, 2015.

BRASIL. Conselho Federal de Medicina. Resolução 1805/2006. Disponível em: $<$ http://www.portalmedico.org.br/resolucoes/cfm/2006/1805_2006.htm > . Acesso em: 25 fev. 2017.

BRASIL. Conselho Federal de Medicina. Resolução 1995/2012. Dispõe sobre as diretivas antecipadas de vontade dos pacientes. Disponível em: $<$ http://www. portalmedico.org.br/resolucoes/CFM/2012/1995_2012.pdf>. Acesso em: 25 fev. 2017.

BRASIL. Código Penal. Decreto-lei no 2.848, de 7 de dezembro de 1940. Disponível em: < http://www.planalto.gov.br/ccivil_03/decreto-lei/ Del2848compilado.htm > . Acesso em: 03 mar. 2017.

CARAMELLI, Paulo; TONIDANDEL, Maira. Como diagnosticar as quatro causas mais freqüentes de demência? Revista Brasileira de Psiquiatria, v. 24, Supl. I, 2002.

CARNEIRO, António Vaz; ANTUNES, João Lobo; FREITAS, António Falcão de. Conselho Nacional de Ética para as Ciências da Vida. Relatório sobre o Estado Vegetativo Persistente. Portugal, 2005. Disponível em: <www.cnecv.pt/admin/ files/data/docs/1273055807_P045_RelatorioEVP.pdf > . Acesso em: 25 fev. 2017.

COOK, Deborah; GRAEME ROCKER. Dying with Dignity in the Intensive Care Unit. The new England Journal of Medicine, june 26, 2014.

DURÁN, Maria Ángeles. La calidad de muerte como componente de la calidad 
de vida. Revista Españhola de Investigaciones Sociológicas. Disponível em: < http://www.reis.cis.es/REIS/PDF/REIS106031167998092686.pdf>. Acesso em: 25 fev. 2017.

GARAY, Oscar. Derechos fundamentales de los pacientes. Buenos Aires: Ad-Hoc, 2003.

KNOBEL, Marcos; SILVA, Ana Lúcia Martins. O paciente terminal: vale a pena investir no tratamento? Einstein, São Paulo, v.2, 2004.

LEVINAS, Emmanuel. Entre nós: ensaios sobre a alteridade. Tradução de Pergentino Pivatto. 5. ed. Petrópolis: Vozes, 2010.

MOUREIRA, Diogo Luna. O reconhecimento e a legitimação da autonomia privada aplicada ao Biodireito. In: CONPEDI. Anais... Manaus: Conpedi. Disponível em: < http://www.conpedi.org.br/manaus/arquivos > . Acesso em: 02 ago. 2014.

RICH, Karen L. Introduction to Bioethics and Ethical Decision Making. In: BUT'TS, Janie B; RICH, Karen L. Nursing Ethics: across the curriculum and into practice. Fourth Edition. Jones \& Bartlett Learning, 2016.

SCHNEEWIND, Jerome B. A invenção da autonomia. Tradução de Magda França Lopes. São Leopoldo: Unisinos, 2005.

SCHNEEWIND, Jerome B. Kant e a moralidade como resultado de nossa autonomia. Revista do Instituto Humanistas Unisinos, São Leopoldo, v. 417, ano XIII, 2013.

SCHRAMM, Fermim Roland. Finitude e Bioética do Fim da vida. Revista Brasileira de Cancerologia, v. 58, n. 1, 2012. Disponível em: < http://www.inca.gov.br/ $\mathrm{rbc} / \mathrm{n} \_58 / \mathrm{v} 01 / \mathrm{pdf} / 1$ artigoopinicaofinitudebioeticafim vida.pdf $>$. Acesso em: $23 \mathrm{fev}$. 2017.

SCHRAMM, Fermim Roland; FLORIANI, Ciro Augusto. Cuidados paliativos: interfaces, conflitos e necessidades. Ciência \& Saúde Coletiva, v. 13, n. Sup 2, 2008.

SEMPRINI, Andrea. Multiculturalismo. Tradução de Laureano Pelegrin. Bauru, SP: EDUSC, 1999.

SOUZA, Ricardo Timm. Sentido e alteridade: dez ensaios sobre o pensamento de 
Emmanuel Levinas. Porto Alegre: EDI-PUCRS, 2000.

TEIXEIRA, Ana Carolina Brochado. Saúde, corpo e autonomia privada. Rio de Janeiro: Renovar, 2010.

VILLAS-BÔAS, Maria Elisa. Da eutanásia ao prolongamento artificial: aspectos polêmicos na disciplina jurídico-penal do final da vida. Rio de Janeiro: Forense, 2005.

Recebido em: 20 de março de 2017 Aceito em: 01 de novembro de 2017 